\title{
Hubungan Pengetahuan dan Sikap Remaja Putri terhadap Perilaku Penanganan Dismenore
}

\author{
Umi Salamah \\ Sekolah Tinggi Ilmu Kesehatan Prima Indonesia \\ Jalan Raya Babelan, KM 9,6, Kebalen, Babelan -Bekasi \\ Email : umi@stikesprimaindonesia.ac.id
}

\begin{abstract}
Abstrak
Disminore adalah nyeri pada bagian bahwa yang bisa menjalar ke punggung bagian bawah dismenore sekunder berarti nyeri panggul yang disebabkan oleh gangguan atau penyakit. . Pada umumnya wanita merasakan keluhan berupa nyeri atau kram perut menjelang haid yang dapat berlangsung hingga 2-3 hari, dimulai sehari sebelum mulai haid. Penelitian ini bertujuan untuk mengetahui apakah ada hubungan antara pengetahuan remaja putri dengan perilaku. Penelitian menggunakan survey dengan pendekatan kuantitatif dengan desain cross sectional, jumlah sampel sebanyak 86 responden. Responden yang berpengetahuan baik sebanyak 67 orang $(77,9 \%)$ dan yang berpengetahuan buruk sebanyak 19 orang (22,1\%). Responden yang mempunyai sikap yang baik sebanyak 53 orang $(61,6 \%)$ dan yang bersikap buruk sebanyak 33 orang $(38,4 \%)$. Responden yang berperilaku baik sebanyak 55 orang $(64 \%)$ dan yang berperilaku buruk sebanyak 31 orang $(46 \%)$. Berdasarkan analisa data didapatkan hasil bahwa variabel yang tidak berhubungan dengan Perilaku siswi terhadap penanganan dismenore adalah Pengetahuan $(\mathrm{P}=0,057)$, sedangkan variabel yang berhubungan adalah variabel Sikap $(\mathrm{P}=0,013)$. Oleh karena itu disarankan untuk meningkatkan kesadaran terhadap kesehatan reproduksi wanita khususnya yang berhubungan dengan penanganan dismenore. Dengan pengadaan kegiatan penyuluhan baik secara individu maupun kelompok yang bekerja sama dengan tenaga instansi kesehatan setempat.
\end{abstract}

Kata Kunci : Dismenore, Pengetahuan, Sikap

\section{Abstract}

Dysminorrhea is pain in the part that can spread to the back of the secondary dysmenorrhea, which means the pelvis is caused by a disorder or disease. In general, women experience complaints in the form of abdominal cramps in question which can last for 2-3 days, starting every day before menstruation begins. This study aims to determine whether there is a relationship between adolescent knowledge with knowledge. Research using quantitative research with cross sectional design, the number of samples was 86 respondents. Respondents who had good knowledge were 67 people (77.9\%) and those who had bad knowledge were 19 people $(22.1 \%)$. Respondents who had good attitudes were 53 people (61.6\%) and worse were 33 people (38.4\%). Respondents who behaved well were 55 people (64\%) and those who behaved badly were 31 people (46\%). Based on the analysis of data obtained from variables not related to student behavior towards handling dysmenorrhea is Knowledge $(P=0.057)$, while the related variable is Attitude variable $(P=0.013)$. Therefore it was agreed to increase awareness of health issued by women related to the treatment of dysmenorrhea. With the provision of extension activities both individuals and groups in collaboration with local health workers.

Keywords: Dysmenorrhea, Knowledge, Attitude 


\section{Pendahuluan}

Kesehatan remaja putri saat ini masih menjadi masalah yang perlu mendapat perhatian. Kesehatan remaja tidak hanya masalah seksual saja tetapi juga menyangkut segala aspek tentang reproduksinya, terutama untuk remaja putri diantaranya adalah perkembangan seks sekunder. ${ }^{(1)}$

Menurut World Health Organization (WHO), remaja adalah penduduk dalam rentang usia 10-19 tahun. Rentang waktu usia remaja ini biasanya dibedakan atas tiga, yaitu Masa remaja awal, 12 - 15 tahun, Masa remaja pertengahan, $15-18$ tahun, Masa remaja akhir, $18-21$ tahun. Tetapi Monks, Knoers, dan Haditono membedakan masa remaja menjadi empat bagian, yaitu masa praremaja 10 - 12 tahun, masa remaja awal $12-$ 15 tahun, masa remaja pertengahan $15-18$ tahun, dan masa remaja akhir $18-21$ tahun $^{(2) .}$

Masa remaja merupakan masa perkembangan pada diri remaja yang sangat penting, diawali dengan matangnya organorgan fisik (seksual) sehingga nantinya mampu bereproduksi. Pada masa remaja terdapat perubahan-perubahan yang terjadi seperti perubahan hormonal, fisik, psikologis maupun sosial, dimana kondisi tersebut dinamakan dengan masa pubertas. ${ }^{(3)}$

Salah satu tanda pubertas pada remaja putri yaitu terjadinya menstruasi Semua wanita mengharapkan dapat menjalani siklus menstruasi yang normal, namun pada kenyataannya banyak diantara mereka merasakan sakit ketika menstruasi. ${ }^{(4)}$

- Pada saat menstruasi, masalah yang dialami oleh hampir sebagian besar wanita adalah rasa tidak nyaman atau rasa nyeri yang hebat. Hal ini biasa disebut dengan nyeri haid (dismenore). Dismenorea masih menjadi masalah kesehatan wanita, padahal tingkat derajat nyeri seseorang berbeda, sehingga dismenorea ini adalah bukan masalah yang serius jika seseorang mengetahui dan dapat menyikapinya dengan baik ${ }^{(3)}$

Dismenore merupakan nyeri ketika menstruasi, dismenore disebabkan oleh ketidakseimbangan hormon progesteron dalam darah, prostaglandin dan faktor stress/psikologi mengakibatkan terjadinya dismenor pada beberapa wanita. Nyeri haid sering dialami oleh sebagian besar wanita. Dari data yang didapat, dismenor ini mengganggu setidaknya $53 \%$ pada usia remaja. Untuk mengatasi hal tersebut sebagian wanita lebih memilih sujud, tidur terlentang, tidak melakukan aktifitas apapun,bahkan sampai dengan menggunakan obat yang berfungsi secara kuratif $^{(5)}$

Dismenorhea terbagi dua yaitu Primer dan sekunder. Dismenorhea primer adalah nyeri menstruasi yang mulai terasa sejak menarche dan tidak ditemukan kelainan dari alat kandungan atau organ lainnya yang berdampak menganggu aktivitas remaja ${ }^{\left({ }^{(6)}\right.}$

Adapun penyebab dismenorhea sekunder biasanya sakitnya disertai dengan gangguan patologis ${ }^{(7)}$

Di Indonesia, angka kejadian dismenore sebanyak 55\% dikalangan usia produktif, dimana $15 \%$ diantaranya mengeluhkan aktivitas menjadi terbatas akibat dismenore. Beberapa penelitian tentang dismenorea pada remaja menunjukkan prevalensi yang cukup tinggi. Prevalensi dismenorea di Asia kurang lebih sekitar (84,2\%), dengan spesifikasi kejadian di Asia Timur laut sebanyak (68,7\%), di Asia Timur Tengah sebanyak $(74,8 \%)$, dan hampir $(50,0 \%)$ di Asia Barat Laut. Prevalensi di Asia Tenggara menunjukkan angka yang berbeda, Malaysia memperkirakan jumlah perempuan yang mengalami dismenorea primer adalah $(69,4 \%)$, Thailand $(84,2 \%)$, dan Indonesia sendiri diperkirakan $(65 \%)$ usia reproduktif mengalami dismenorea primer. Di Indonesia dismenorea primer menyebabkan remaja perempuan $(59,2 \%)$ terjadi penurunan aktivitas, $(5,6 \%)$ bolos sekolah atau kerja, dan sebanyak $(35,2 \%)$ tidak merasa terganggu (2)

Dismenore merupakan nyeri ketika menstruasi, dismenore disebabkan oleh ketidakseimbangan hormon progesteron dalam darah, prostaglandin dan faktor stress/psikologi mengakibatkan terjadinya dismenor pada beberapa wanita. Nyeri haid sering dialami oleh sebagian besar wanita. Dari data yang didapat, dismenor ini mengganggu setidaknya $53 \%$ pada usia remaja. Untuk mengatasi hal tersebut sebagian wanita lebih memilih sujud, tidur terlentang, tidak melakukan aktifitas apapun,bahkan sampai dengan menggunakan obat yang berfungsi secara kuratif ${ }^{(5)}$

Dismenore merupakan nyeri yang muncul saat terjadinya mentruasi pada perempuan. Yang dapat disarakan sebagai gangguan aktivitas sehari-hari. Dismenorhea dapat dipengaruhi dengan adanya aktivitas fisik, kondisi psikologis yang tidak adekuat serta 
beberapa konsisi lain seperti karakteristik seseorang yang sedang mangalami menstruasi.

Pada remaja dengan dismenore primer akan dijumpai peningkatan produksi prostaglandin oleh endometrium yang merupakan stimulan kontraksi miometrium kuat serta efek vasokontriksi pembuluh darah. Beberapa faktor risiko yang berhubungan dengan beratnya gejala dismenore adalah usia yang lebih muda saat terjadinya menarche periode menstruasi yang lebih lama, banyaknya darah yang keluar selama menstruasi, perokok, riwayat keluarga dengan dismenore, depresi atau anxietas dan obesitas. ${ }^{(9)}$

Menstruasi menyebabkan gangguan psikologis atau fisik. Sesungguhnya mereka mungkin menderita berbagai subtype ketegangan sindrom premenstruasi. Perubahan suasana hati yang paling banyak dirasakan oleh wanita pada masa sebelum menstruasi tersebut datang dan mereda saat menstruasi tiba. Gejala fisik yang nampak misalnya kenaikan berat badan, buah dada yang nyeri, sakit kepala, migrain, pegal dan nyeri, gangguan pada kulit serta nafsu makan yang berlebihan. Gejala psikologis yang muncul misalnya ketegangan, rasa cepat marah, depresi, kelesuan, dan berkurangnya daya konsentrasi ${ }^{(9)}$

Pada saat mengalami dismenorhea, mereka tidak berkonsentrasi dalam proses belajar-mengajar sampai tertidur didalam kelas bahkan sampai meminta izin untuk pulang karena tidak tahan dengan nyeri yang dialami $^{(10)}$

Adapun faktor yang dapat mempengaruhi nyeri saat menstruasi diantaranya menarche pada usia dini, siklus haid yang panjang, merokok atau alkohol, aktivitas atau olahraga yang kurang, gizi atau obesitas, dan stress. Gizi atau obesitas merupakan faktor yang mempengaruhi terjadinya nyeri perut atau dismenore. hal ini didukung dengan kebiasaan mengkonsumsi makanan yang tidak sesuai seperti kudapan atau junk food. Mengkonsumsi yang berlemak dapat meningkatkan hormon prostaglandin yang dapat menyebabkan nyeri di bagian perut bawah atau dismenore. ${ }^{(1)}$

Untuk menghilangkan rasa sakit yang disebabkan oleh dismenore dapat dilakukan dengan menggunakan obat-obat golongan analgetik seperti aspirin, asam mefenamat, parasetamol, kofein, dan feminax, obat-obat merek dagang yang beredar di pasaran antara lain novalgin, ponstan, sering juga digunakan untuk mengurangi keluhan. Ada juga yang menggunakan obat tradisional seperti air daun sirih, daun pepaya, rimpang kunyit dan lain-lain. Sebagian besar perempuan yang mengalami ${ }^{(12)}$

Dismenore sering menggunakan obat merek dagang yang berfungsi sebagai analgetik seperti asam mefenamat, ibu profen, aspirin, paracetamol, diklofenak, dan lain-lain. Secara umum efek samping obat analgetik tersebut adalah gangguan pada saluran cerna, seperti mual, muntah, dispepsia, diare, dan gejala iritasi lain terhadap mukosa lambung, serta eritema kulit dan nyeri pada kepala ${ }^{(12)}$

Penanganan disminore mendapatkan hasil yang tinggi dilakukan dengan minum obat analgesic dan di ikuti minum minuman yang hangat, mengkompres perut dengan air hangat, berbaringlah miring dengan lutut menekuk, memijat perut dengan lembut secara perlahan, minum yang hangat dan berolahraga dapat mengurangi nyeri ${ }^{(13)}$

Berdasarkan studi pendahuluan yang telah dilakukan oleh peneliti, dilakukan penyebaran kuesioner terhadap 10 siswi yang sudah mengalami menstruasi, ternyata pengetahuan mereka tentang disminore berbeda-beda yaitu sebanyak 7 orang $(70 \%)$ belum bisa menjawab dengan baik dan sebanyak 3 (30\%) orang sudah menjawab dengan baik.

\section{Metode}

Penelitian ini bersifat kuantitatif, dengan metode penelitian survei analitik yang bertujuan untuk survei atau penelitian. Desain penelitian yang digunakan yaitu cross sectional yang bertujuan untuk mempelajari dinamika korelasi antara faktor-faktor resiko dengan efek dengan cara pendekatan atau pengumpulan data sekaligus pada suatu saat ${ }^{(6)}$

Populasi adalah keseluruhan objek penelitian atau objek yang diteliti. Dalam penelitian ini adalah siswi berjumlah 68 orang. Dalam penelitian ini peneliti mengambil dengan teknik accidental sampling ${ }^{(14)}$ 
Hasil

Tabel 1. Distribusi Frekuensi berdasarkan Pengetahuan, Sikap dan Perilaku remaja putri terhadap perilaku penanganan dismenore tahun 2019

\begin{tabular}{|c|c|c|}
\hline Variabel & $\mathbf{N}$ & $\%$ \\
\hline \multicolumn{3}{|l|}{ Pengetahuan } \\
\hline Baik & 67 & 77,9 \\
\hline Buruk & 19 & 22,1 \\
\hline \multicolumn{3}{|l|}{ Sikap } \\
\hline Baik & 53 & 61,6 \\
\hline Buruk & 33 & 38,4 \\
\hline \multicolumn{3}{|l|}{ Perilaku } \\
\hline Baik & 31 & 36,0 \\
\hline Buruk & 55 & 64,0 \\
\hline
\end{tabular}

Tabel 2. Hubungan Pengetahuan, Sikap Remaja Putri terhadap Perilaku penanganan Dismenore

\begin{tabular}{llllll}
\hline Variabel & \multicolumn{3}{c}{ Perilaku } & & \\
\cline { 2 - 5 } & Baik & \multicolumn{5}{c}{ Buruk } & P value \\
\cline { 2 - 5 } & $\mathbf{N}$ & $\mathbf{\%}$ & $\mathbf{N}$ & $\mathbf{\%}$ & \\
\hline Pengetahuan & 28 & 3,5 & 39 & 45,3 & 0,057 \\
Baik & 3 & 32,6 & 16 & 18,6 & \\
Buruk & 25 & 29,1 & 28 & 31,4 & 0,013 \\
\hline Sikap & 6 & 7,0 & 27 & 32,6 & \\
Baik & & & & & \\
Buruk & & &
\end{tabular}

\section{Pembahasan}

Pada hasil penelitian ini diketahui bahwa respnden dengan pengetahuan baik sebanyak 67 orang $(77,9 \%)$ meskipun hasil penelitian ini menunjukkan bahwa responden dengan pengetahuan baik namun memiliki perilaku buruk sebanyak 39 orang $(45,3 \%)$. Setelah dilakukan uji chi square didapatkan nilai $\mathrm{P}$ 0,057 artinya tidak ada hubungan signifikan antara pengetahuan dengan perilaku penanganan dismenore. Pengetahuan seseorang tentang suatu objek juga mengandung dua aspek, yaitu aspek positif dan negatif. Kedua aspek inilah yang akhirnya akan menentukkan perilaku seseorang terhadap objek tertentu. Semakin banyak aspek positif terhadap objek yang diketahui, maka akan menumbuhkan sikap yang semakin positif terhadap objek tersebut (15). Tahu diartikan sebagai mengingat suatu materi yang telah dipelajari sebelumnya, mengingat kembali termasuk (recall) terhadap suatu yang spesifik dari seluruh bahan atau rangsangan yang diterima $^{(15)}$

Pada penelitian ini, siswi dianggap baru mengetahui tentang dismenore dan penanganannya tanpa menginterpretasikan apa yang telah diketahui dalam hal menangani dismenore yang dialami. Hasil responden yang bersikap baik sebanyak 53 orang $(61,6 \%)$ dan yang bersikap buruk sebanyak 33 orang $(38,4 \%)$.

Responden pada penelitian ni memiliki sikap yang baik sebesar 53 orang $(61.6 \%)$ dan responden yang memiliki sikap yang baik dengan memiliki perilaku yang buruk 28 orang $(32,6 \%)$ dan responden yang memiliki sikap yang buruk dengan perilaku buruk sebanyak 27 orang $(31,4 \%)$. Setelah dilakukan uji chi square didapatkan nilai $\mathrm{P} 0,013$ artinya ada hubungan antara pengetahuan dengan perilaku penanganan dismenore. Hal ini sesuai dengan teori yang mengatakan bahwa Sikap merupakan predisposisi untuk melakukan atau tidak melakukan suatu perilaku tertentu, sikap lebih suatu proses kesadaran yang sifatnya individual. Sikap yang positif akan memicu sesorang untuk melakukan tindakan ${ }^{(3)}$

Penelitian ini sejalan dengan penelitan yang dilakukan oleh Purnomo di SMPN 09 Pekalongan Utara yang mengemukakan bahwa 19 orang remaja putri atau 47,5\% memiliki sikap baik dengan perilaku yang buruk dengan $\mathrm{P}$ value $<0,05$ yang berarti adanya hubungan 
antara pengetahuan dengan perilaku dalam menangani dismenore ${ }^{(2)}$. Pengalaman pribadi yang telah dan sedang kita alami akan ikut membentuk dan mempengaruhi penghayatan kita terhadap stimulus sosial. Tanggapan akan menjadi salah satu dasar terbentukknya sikap. Untuk dapat mempunyai tanggapan dan penghayatan, seseorang harus mempunyai pengalaman yang berkaitan dengan objek psikologis. Karena terbatasnya kapasitas otak manusia dalam memproses informasi, maka orang cendrung untuk bergantung pada pengetahuan yang didapat dari pengalaman dan informasi dari lingkungan. ${ }^{(2)}$

\section{Kesimpulan}

Tingkat pengetahuan tentang dismenore pada siswi sebagian besar berpengetahuan baik yaitu 67 orang $(77,9 \%)$. Sikap terhadap dismenore pada siswi sebagian besar memiliki sikap baik yaitu 53 orang $(61,6 \%)$. Perilaku dismenore pada siswi berperilaku baik yaitu 31 orang (36\%).

Tidak ada hubungan antara pengetahuan remaja putri dengan perilaku penanganan dismenore pada siswi. Ada hubungan antara sikap remaja putri dengan perilaku penanganan dismenore pada siswi.

\section{Saran}

Diharapkan tenaga kesehatan dapat memberikan pendidikan kesehatan tentang dismenore sehingga dapat meningkatkan kesadaran terhadap kesehatan reproduksi wanita khusunya berhubungan dengan penanganan dismenorhea

\section{Daftar Pustaka}

1. Kasumayanti E. Faktor-faktor yang berhubungan dengan kejadian dismenore di SMAN 5 Pekanbaru. STIKes Tuanku Tambusai. 2015;(4):20-8.

2. Purnomo I. Hubungan pengetahuan dan sikap remaja putri dengan penanganan keluhan nyeri haid ( dysmenorhe ) di SMPN 09 kelas viii kota Pekalongan. Ilmu Kesehat Univ Pekalongan. 2011;11.

3. Nurjanah S. Analisa determinan pengetahuan dan sikap remaja putri tentang dismenorhea. J SMART Kebidanan. 2018;5(1):83.

4. Aziza N. Dismenorhea Pada Mahasiswa Anemia Di Prodi Kebidanan Poltekkes Kemenkes Tanjungkarang. J Keperawatan. 2013;IX(1):1-4.
5. Rahayu MA, Suryani L, Marlina R. Efektifitas Senam Dismenore Dalam Mengurangi Dismenore Pada Mahasiswa. J Ilm Solusi [Internet]. 2014;1.2(2):56-61. Available from: download.portalgaruda.org/article.php?...PEN GARUH SENAM

6. Rahmadhayanti E, Rohmin A. Hubungan Status Gizi dan Usia Menarche dengan Dismenorhea Primer pada Remaja Putri Kelas XI SMA Negeri 15 Palembang. J Kesehat. 2016;7(2):255

7. Tampake RA, Wagey F, Rarung M. Pengetahuan dan sikap remaja terhadap dismenorhea di SMP PNIEL Manado. eCliniC. 2014;2(2).

8. Rejeki S. Gambaran tingkat stress dan karakteristik remaja putri dengan kejadian dismenorhea primer. J Kebidanan. 2019;8(1):50.

9. Manuaba. Ilmu kebidanan. 2008.

10. Rohmawati W, Wulandari DA. Faktor-Faktor yang Berhubungan dengan Nyeri Dismenore Primer pada Siswi Di SMA Negeri 15 Semarang. J Bidan Cerdas. 2019;2(2):84.

11. Pratiwi H, Rodiani R. Obesitas sebagai Resiko Pemberat Dismenore pada Remaja. Med J Lampung Univ [Internet]. 2015;4(9):108-12. Available from: http://jukeunila.com/majority/

12. Marni. Perbedaan Antara Relaksasi Dan Kompres Terhadap Penurunan Skala Nyeri Haid (Pada Mahasiswa Di Akper Giri Satria Husada Wonogiri) _ Program Pascasarjana UNS Solo [Internet]. 20 Mei 2013. 2013. Available from: http://pasca.uns.ac.id/?p=3509

13. Rohmatunidha. Tingkat kecemasan remaja putri terhadap dismenorhea beserta upaya penanganan dismenorhea pada siswi kelas XI di SMAN 1 Driyorejo Kabupaten Gresik. ADLN Perpust Univ Airlangga. 2016;

14. Arikunto. Metodelogi Penelitian, Suatu Pengantar Pendidikan. In: Rineka Cipta, Jakarta. 2019. p. 21.

15. Notoatmodjo S. Promosi Kesehatan dan Perilaku Kesehatan Edisi 2012. Rineka Cipta. 2012. 